\title{
Feeding flow and membranelle filtration in ciliates
}

Rode, Mads; Kiørboe, Thomas; Andersen, Anders

Published in:

Physical Review Fluids

Link to article, DOI:

10.1103/PhysRevFluids.7.023102

Publication date:

2022

Document Version

Peer reviewed version

Link back to DTU Orbit

Citation (APA):

Rode, M., Kiørboe, T., \& Andersen, A. (2022). Feeding flow and membranelle filtration in ciliates. Physical Review Fluids, 7(2), [023102]. https://doi.org/10.1103/PhysRevFluids.7.023102

\section{General rights}

Copyright and moral rights for the publications made accessible in the public portal are retained by the authors and/or other copyright owners and it is a condition of accessing publications that users recognise and abide by the legal requirements associated with these rights.

- Users may download and print one copy of any publication from the public portal for the purpose of private study or research.

- You may not further distribute the material or use it for any profit-making activity or commercial gain

- You may freely distribute the URL identifying the publication in the public portal

If you believe that this document breaches copyright please contact us providing details, and we will remove access to the work immediately and investigate your claim. 


\title{
Feeding flow and membranelle filtration in ciliates
}

\author{
Mads Rode, Thomas Kiørboe, and Anders Andersen ${ }^{1}$ \\ Centre for Ocean Life, National Institute of Aquatic Resources, Technical University of \\ Denmark, DK-2800 Kgs. Lyngby, Denmark
}

\begin{abstract}
Ciliates are ubiquitous in the marine environment and important consumers of phytoplankton and flagellates. The feeding on suspended food particles in ciliates is complex and relies typically on coordinated motion in bands of transversal rows of cilia known as membranelles. Many ciliates are upstream collectors that use a single membranelle band to both generate feeding flow, retain food particles, and transport them to the mouth region. To explore a representative upstream collector, we consider the ciliate Euplotes vannus. We determine the clearance rate using particle tracking and estimate the flow-generating force by fitting a point force model to the observed flow. To obtain a mechanistic understanding of feeding flow and particle retention, we use high-speed video-microscopy. The cilia move parallel to the membranelle band towards the mouth region in the power strokes, and a metachronal wave propagates away from the mouth region parallel to the band and outwards along the membranelles. A gap therefore opens between neighboring membranelles from the inner side of the band where the mouth region is located, and while food particles are retained, water is drawn in and pushed outwards across the membranelle band as the gap closes from the inner side. We suggest a model that rationalizes our observations and quantifies the mechanism by which the membranelle band can both generate feeding flow and retain food particles. The model compares favorably with our observations and suggests a trade-off between the clearance rate and the membranelle gap that determines the lower cut-off in the prey size spectrum. We quantify the trade-off and discuss the ecological significance of our findings.
\end{abstract}

\footnotetext{
${ }^{1}$ Author for correspondence. E-mail: aanders@aqua.dtu.dk
} 


\section{Introduction}

Organisms that feed on small suspended food particles play important roles in marine food webs and include unicellular flagellates and ciliates, copepods, sponges, bivalves, gelatinous plankton, and the larvae of many benthic organisms [1,2]. The typical unicellular suspension feeder generates a flow from which food particles are retained and transported to the cell surface where they are phagocytized [3]. To retain food particles and overcome the viscous forces that impede predator-prey contact at low Reynolds number, unicellular organisms use flagella, cilia, or tentacles extending from the cell $[4,5]$. In flagellates, the feeding flow is typically generated by a single flagellum, whereas ciliates feed using coordinated, metachronal motion of hundreds of cilia $[3,6,7]$. The cilia motion and interaction with particles is challenging to observe, and the complex feeding modes in ciliates are not fully understood. Here, we focus on ciliates that use a single band of cilia to both generate the feeding flow, retain the food particles, and transport them to the mouth region.

The fluid dynamics of microorganisms has mainly been explored in the context of swimming and uptake of dissolved nutrients [8-11], and it has received less attention in relation to feeding on particulate matter [1-5]. The swimming of ciliates has been described in models like the squirmer model that represents the collective action of cilia covering a cell surface $[12,13]$, and using models that resolve the fluid dynamics of individual cilia [14-16]. The individual cilium is a slender organelle that extends from the cell surface and beats periodically with each cycle consisting of a power stroke and a return stroke $[17,18]$. In the power stroke, the cilium is stretched out, whereas it is bent and close to the surface in the return stroke, and this gives rise to a net transport of fluid in the direction of the power stroke [14]. Closely spaced cilia that are distributed over a surface or organized in a band beat metachronally, i.e., with the same period and structured phase shifts between neighbors. The resulting collective motion appears as a metachronal wave that propagates over the surface [19-22]. Most ciliates are purely heterotrophic organisms that feed on suspended food particles such as phytoplankton and flagellates [3], while some are mixotrophs that also take up dissolved nutrients and harvest the photosynthetic apparatus of other organisms to do photosynthesis [23-25].

The exploration of feeding on suspended food particles in ciliates was pioneered by studies of the sessile ciliate Vorticella sp. and the seminal work by Fenchel on different species with characteristic feeding modes [3, 6, 7, 26-28]. Typical suspension feeding ciliates are characterized as either upstream or downstream collectors [3]. In upstream collection, a single band of cilia both generates the feeding flow and retains the food particles, whereas in downstream collection, one band of cilia generates the flow while the food particles are retained by another band located downstream [29]. The two feeding modes are found among a wide variety of invertebrate ciliary suspension feeders [30]. Among the ciliates, the species Euplotes moebiusi and Uronema are examples of upstream collectors, and Vorticella and Cyclidium are described as downstream collectors [3]. Due to 
small spacing of the downstream filter, downstream collectors are generally able to retain smaller food particles than upstream collectors, but this happens at the cost of higher filter resistance and lower clearance rate, i.e., the volume of water cleared for food particles per unit time [3].
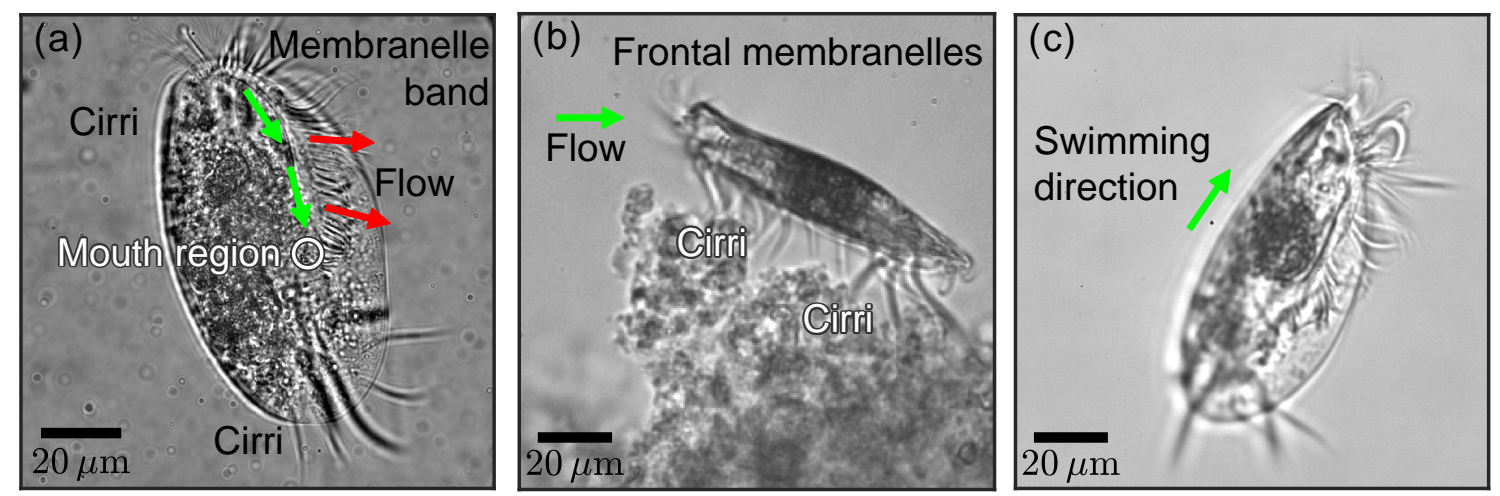

Figure 1: Microscope images of Euplotes vannus. (a) Ventral view of an individual walking on the cover glass. The membranelle band is to the right, starting at the front of the cell (up) and twisting towards the mouth region at the center of the cell. The flow along the inner side of the band towards the mouth region and the flow outwards through the band are indicated by green and red arrows, respectively. Large cirri are visible on the back. (b) Profile view of an individual walking on a lump of material using its large cirri. The feeding flow is towards the front of the cell as indicated by the green arrow. (c) Freely swimming individual with helical trajectory. The instantaneous swimming direction is indicated by the green arrow.

As study organism, we consider the heterotrophic ciliate Euplotes vannus (Fig. 1 and supplemental material, Videos S1-S3). We have chosen to focus on E. vannus to explore a representative upstream collecting ciliate. The cell is elongated and flattened, and there is a clear differentiation between the dorsal and ventral side [31-33]. On the ventral side, the cell has approximately 20 cirri and a band of membranelles. Each cirri consists of tens of cilia that are joined together, and each membranelle is a row of closely spaced cilia. The ciliate swims with a helical trajectory, but primarily it sits and walks on surfaces using the cirri as legs $[34,35]$. The membranelle band starts at the front of the organism, twists towards the center of the cell, and ends at the mouth region. The membranelles beat periodically with power and return strokes primarily parallel to the membranelle band, and a metachronal wave propagates both along the band and the individual membranelles $[3,7]$. However, observations of membranelle motion and interaction with particles are sparse, and a thorough understanding of the membranelle function in E. vannus and other ciliates with upstream collection is lacking. For example, it is not clear why water passes through the filter rather than bypassing it along a route of lower flow resistance. 
The aim of our work on E. vannus is to quantify the feeding flow and the force needed to generate it, and to provide a mechanistic description of the metachronal motion and particle retention in the membranelle band. We build on and expand the previous work on Euplotes sp. by Fenchel [3, 7], and we provide detailed observations of feeding flow and membranelle motion using high-speed video-microscopy and particle tracking. We determine the clearance rate and estimate the flow-generating force using a point force model of the observed feeding flow [3, 36-40]. Furthermore, we develop a model of the individual ciliary beat and the coordinating metachronal wave, which rationalizes the observed membranelle motion and accurately predicts the observed clearance rate. The model suggests a trade-off between the clearance rate and the membranelle gap that determines the lower cut-off in the prey size spectrum. We quantify the trade-off and estimate the encounter rate, and we discuss the ecological significance of our findings in relation to the prey size spectra reported in the literature for ciliates and other suspension feeders.

\section{Materials and methods}

\section{$2.1 \quad$ Experimental organisms and observations}

The E. vannus culture was acquired from the Culture Collection of Algae and Protozoa, SAMS Limited, Scottish Marine Institute, United Kingdom (Table 1). The culture was grown in artificial sea water at $18^{\circ} \mathrm{C}$ and diluted $2-3$ times per year in $65 \mathrm{~mL}$ flasks with artificial sea water and autoclaved rise grains to serve as bacterial substrate. Observations were made in a temperature-controlled room at $20^{\circ} \mathrm{C}$ using a custom-built, circular sample chamber with inner diameter $5 \mathrm{~mm}$ and height $2 \mathrm{~mm}$. The chamber was sealed at the bottom with a circular glass coverslip and silicone grease, filled with the culture in artificial sea water, and covered with a glass coverslip. For high-speed video-microscopy we used an Olympus IX71 inverted microscope with $10 \times, 40 \times$, and $100 \times$ magnification, and a Phantom Miro LAB 320 high-speed video camera $(1920 \times 1200$ pixels $)$ with frame rates of $200 \mathrm{fps}$ to observe the feeding flow and $500 \mathrm{fps}$ and $1000 \mathrm{fps}$ for the membranelle filtration. To visualize the feeding flow we used neutrally buoyant, spherical polystyrene tracer particles (microParticles GmbH, Berlin, Germany) with diameter $1 \mu \mathrm{m}, 2 \mu \mathrm{m}$, or $4 \mu \mathrm{m}$, and concentrations in the range $1.2 \times 10^{7}-2.4 \times 10^{8}$ particles $\mathrm{mL}^{-1}$.

Tracer particles that could be identified automatically were tracked using customwritten code in MATLAB, and tracer particles that could not be identified automatically, e.g., in front of the cell body, were tracked manually using ImageJ. The particle velocities were obtained by differentiating the particle positions with respect to time using a leastsquares, five-point finite difference scheme designed to minimize the noise error [41, 42]. 


\subsection{Point force model of feeding flow}

We model the feeding flow towards the ciliate as the low-Reynolds-number flow due to a point force that acts in the infinite half-space above a plane surface with no-slip boundary condition [3, 38-40]. The governing equations are the time-independent Stokes equations:

$$
-\nabla p+\mu \nabla^{2} \boldsymbol{v}=\mathbf{0}, \quad \boldsymbol{\nabla} \cdot \boldsymbol{v}=0
$$

where $p$ denotes the pressure field, $\boldsymbol{v}$ the velocity field, and $\mu$ the viscosity. (Table 2 provides a glossary of symbols.) We assume that the surface lies in the $x y$-plane, and that the point force is directed parallel to the surface in the $x$-direction. The problem was solved analytically by Blake and coworkers [36, 37], and the solution can be expressed as a superposition of the Stokeslet flow due to the point force acting in an infinite fluid domain and an image system ensuring that the no-slip boundary condition at the surface

is satisfied. The parameters are the magnitude of the point force, $F$, and its height above the surface, $h$. Plots and fits of the solution were made using the software Mathematica. 
Table 1. Parameters for Euplotes vannus. The number $n$ is the number of observations, and the cell volume is based on length, width, and thickness information from different individuals.

\begin{tabular}{|c|c|c|}
\hline parameter & value & $\mathbf{n}$ \\
\hline cell length $(\mu \mathrm{m})$ & $88 \pm 5$ & 11 \\
\hline cell width $(\mu \mathrm{m})$ & $49 \pm 4$ & 8 \\
\hline cell thickness $(\mu \mathrm{m})$ & $23 \pm 3$ & 4 \\
\hline cell volume $\left(\mu \mathrm{m}^{3}\right)$ & $(5.1 \pm 0.9) \times 10^{4}$ & - \\
\hline membranelle band length, inner ( $\mu \mathrm{m})$ & $65 \pm 3$ & 5 \\
\hline membranelle band length, outer $(\mu \mathrm{m})$ & $120 \pm 5$ & 5 \\
\hline membranelle band length, average, $L(\mu \mathrm{m})$ & $92 \pm 6$ & 5 \\
\hline membranelle number & $40 \pm 3$ & 5 \\
\hline membranelle spacing, $d(\mu \mathrm{m})$ & $2.3 \pm 0.2$ & 5 \\
\hline membranelle height, $a(\mu \mathrm{m})$ & $20 \pm 1$ & 5 \\
\hline membranelle width, $W(\mu \mathrm{m})$ & $12 \pm 2$ & 5 \\
\hline beat frequency, $f(\mathrm{~Hz})$ & $31 \pm 5$ & 6 \\
\hline cirri length, back $(\mu \mathrm{m})$ & $35 \pm 3$ & 6 \\
\hline 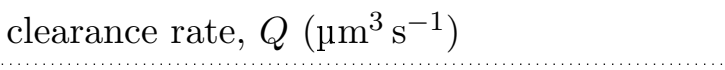 & $(9 \pm 2) \times 10^{5}$ & 1 \\
\hline cell-volume specific clearance rate $\left(\mathrm{d}^{-1}\right)$ & $(1.7 \pm 0.3) \times 10^{6}$ & 1 \\
\hline force height, $h(\mu \mathrm{m})$ & 30 & 1 \\
\hline force magnitude, $F(\mathrm{pN})$ & $260 \pm 4$ & 1 \\
\hline
\end{tabular}


Table 2. Glossary of symbols.

\begin{tabular}{|c|c|}
\hline$a$ & membranelle height \\
\hline$A, A_{\max }$ & amplitude and maximum amplitude \\
\hline$b$ & width of flow region along membranelle band \\
\hline$C$ & size-specific mass concentration of food particles \\
\hline$C_{0}$ & mass concentration of food particles within each decade \\
\hline$d, d_{\mathrm{p}}, d_{\mathrm{r}}$ & membranelle spacing and gap in power and return stroke \\
\hline$E$ & encounter rate \\
\hline$f$ & beat frequency \\
\hline$F$ & force magnitude \\
\hline$h$ & force height \\
\hline$k_{x}, k_{y}$ & wave vector components \\
\hline$l$ & upper cut-off in food particle size spectrum \\
\hline$L$ & membranelle band length \\
\hline$N$ & number of membranelles after which the phase is repeated \\
\hline$p$ & pressure \\
\hline$q$ & cilium tip position \\
\hline$Q$ & clearance rate \\
\hline$T$ & beat period \\
\hline$V$ & volume between membranelles \\
\hline$W$ & membranelle width \\
\hline $\boldsymbol{v}, v_{x}, v_{y}$ & velocity and velocity components \\
\hline$\alpha$ & fractional duration of power stroke \\
\hline$\beta$ & dimensionless amplitude parameter \\
\hline$\mu$ & viscosity \\
\hline$\varphi$ & phase \\
\hline$\chi$ & phase shift \\
\hline$\omega$ & angular beat frequency \\
\hline
\end{tabular}




\section{Results}

\subsection{Feeding flow and clearance rate}

Euplotes vannus creates a feeding flow towards the membranelle band while moving around or sitting still with its large cirri on the sample chamber or lumps of organic material (supplemental material, Videos S4-S5). The flow is predominantly parallel to the surface on which the organism sits, and it qualitatively resembles the Stokeslet flow due to a point force with the highest flow speeds near the flow-generating cilia (Fig. 2). The ciliates stay at a given location for typically $1 \mathrm{~s}$ to $10 \mathrm{~s}$, but individuals can sit up to several minutes when partly shielded within large lumps of organic material. The large cirri position the cell body approximately $30 \mu \mathrm{m}$ above the surface.
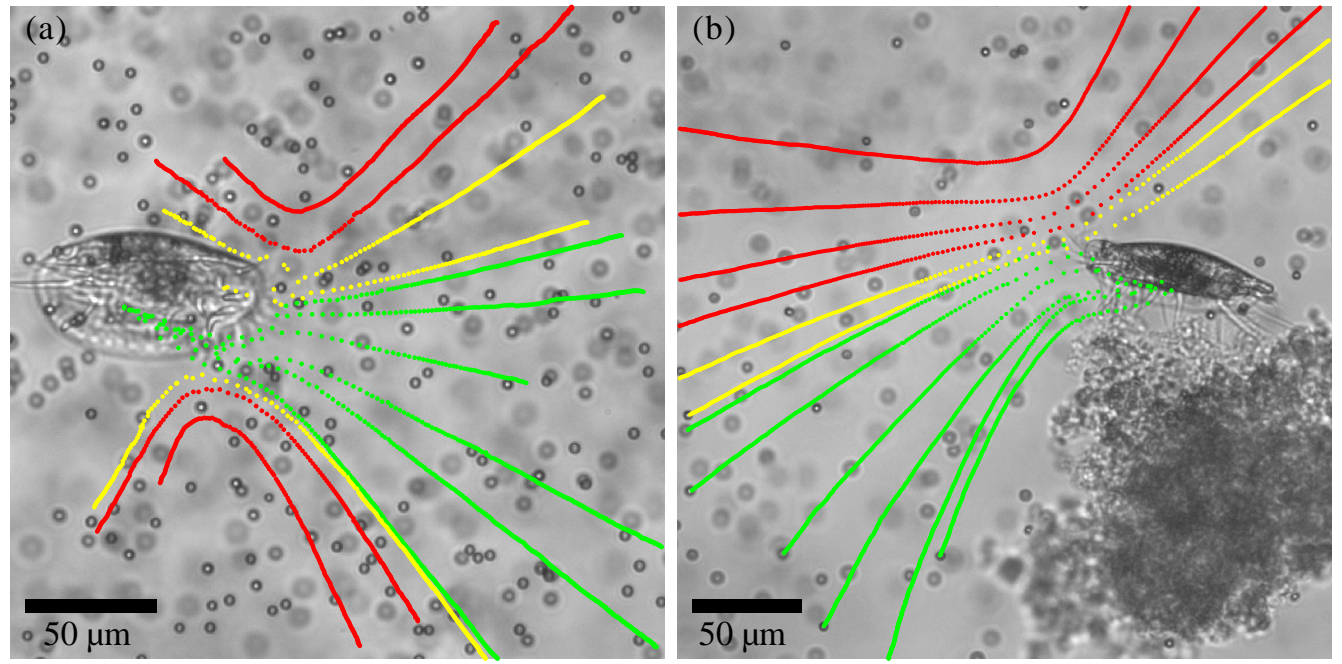

Figure 2: Representative particle tracks visualizing the feeding flow. The tracer particles are either carried past the ciliate (red), interacting with the frontal membranelles but lost and not carried along the membranelle band towards the mouth region (yellow), or transported to the mouth region (green). (a) Ventral view of an individual on the coverslip with flow from right to left, and (b) profile view of an individual on a lump of material with flow from left to right. The particles are $4 \mu \mathrm{m}$ in diameter and shown with $10 \mathrm{~ms}$ time intervals. The individual slowly rotates by $25^{\circ}$ in the video sequence used for panel (a), and each track has been oriented to match the cell orientation when the particle reaches the mouth region or its point of closest approach.

To estimate the clearance rate of the feeding flow, we focus on the case where the organism is sitting on the coverslip [Fig. 3(a)]. The origin of the coordinate system is positioned in front of the cell, and the $x$-axis is oriented along the main flow direction. The profile of the velocity component $v_{x}$ along the transect at $x=-50 \mu \mathrm{m}$ is roughly 

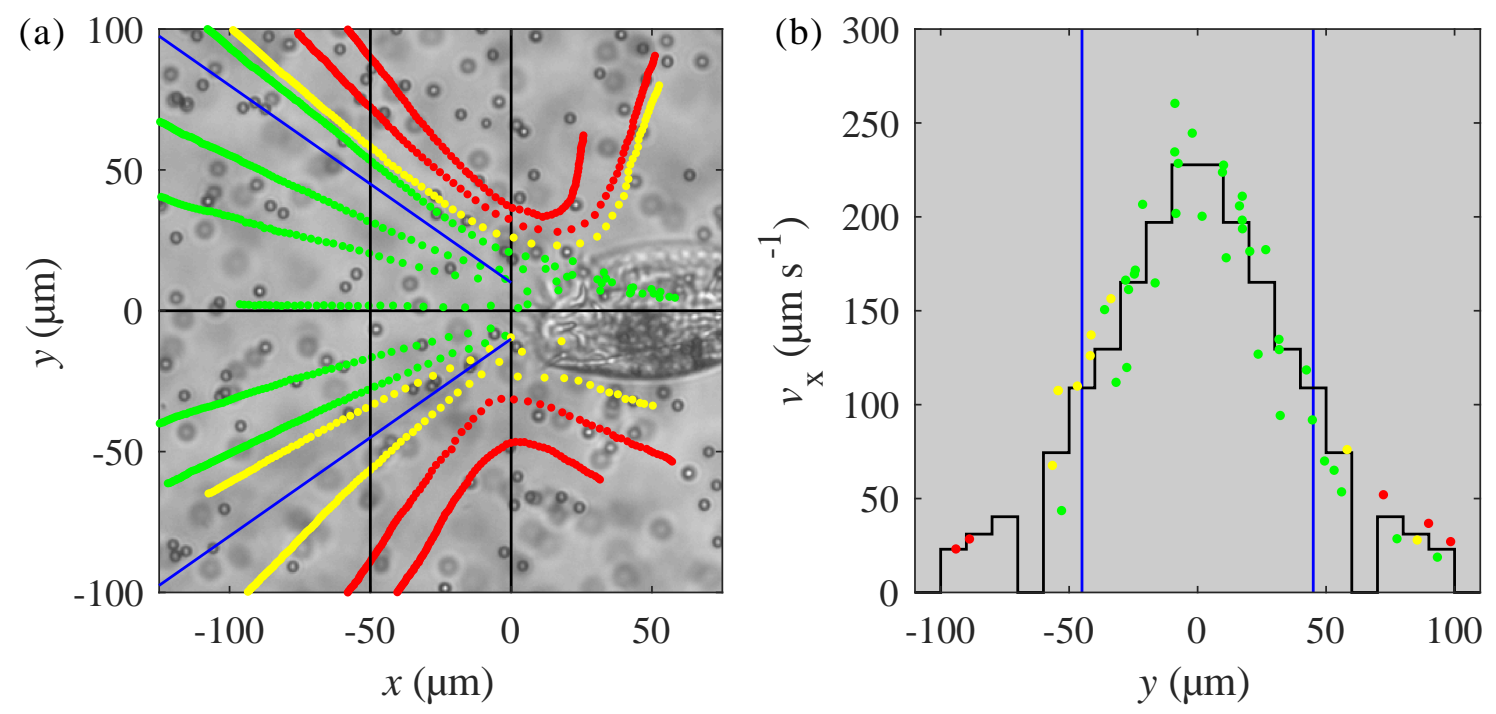

Figure 3: Velocity profile of the feeding flow. (a) Ventral view of an individual on the coverslip with flow in the positive $x$-direction. The tracks are color-coded as in Fig. 2, and the blue lines delimit the clearance zone. The particles are $4 \mu \mathrm{m}$ in diameter and shown with $20 \mathrm{~ms}$ time intervals. To take into account that the individual slowly rotates during the video sequence, each track has been oriented to match the cell orientation when the particle reaches the mouth region or its point of closest approach. (b) Velocity profile along the transect with $x=-50 \mu \mathrm{m}$. The particle velocities are shown as dots, and the stepwise averaged velocity profile is left-right symmetrized and made with $10 \mu \mathrm{m}$ steps.

symmetric with respect to the $x$-axis [Fig. 3(b)]. We estimate the clearance zone using the particles that are classified as retained, and we assume that it is delimited by the blue lines. The observation plane is at the same height above the surface as the organism, and for simplicity we assume a circular clearance disk $[3,40]$. To obtain the clearance rate we numerically integrate $v_{x}$ over the clearance disk using the approximation:

$$
Q=\pi \Delta^{2}\left[\sum_{n=1}^{4}(2 n-1)\left\langle v_{x}\right\rangle_{n}+4.25\left\langle v_{x}\right\rangle_{5}\right],
$$

where $\Delta=10 \mu \mathrm{m}$ is the step width of the velocity profile and $\left\langle v_{x}\right\rangle_{n}$ the average of the velocity component in the $n$-th bin counting from the center. We find the clearance rate $Q=(9 \pm 2) \times 10^{5} \mathrm{\mu m}^{3} \mathrm{~s}^{-1}$, which corresponds to the cell-volume specific clearance rate $(1.7 \pm 0.3) \times 10^{6} \mathrm{~d}^{-1}$ (Table 1$)$. The uncertainty in the clearance rate is estimated based on the uncertainty in the limits of the clearance zone which we estimate to be $\pm 5 \mu \mathrm{m}$ [Fig. 3(b)]. 


\subsection{Point force model and flow-generating force}

(a)

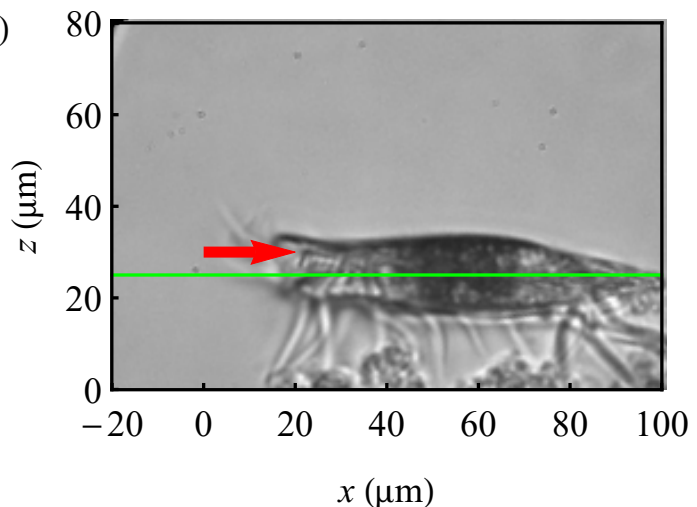

(c)

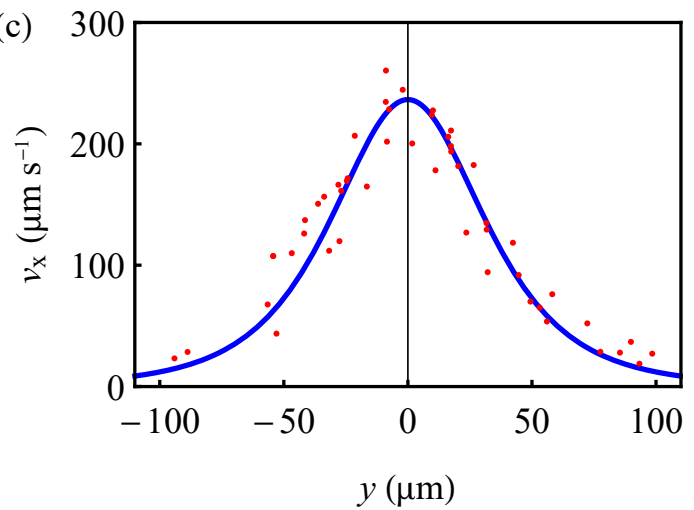

(b)

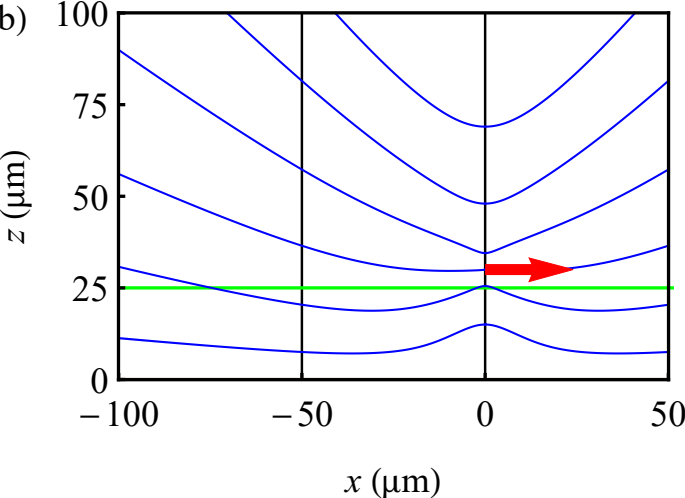

(d)

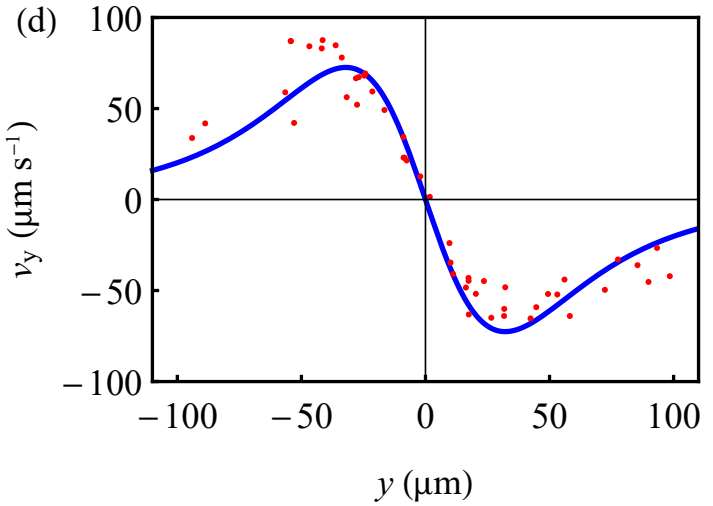

Figure 4: Point force model and estimation of the flow-generating force. (a) Profile view of an individual showing the assumed posture when sitting on a flat surface. The red arrow indicates the point force position and direction and the green line the focal plane. (b) Model streamlines (blue) in the $x z$-plane with $h=30 \mu \mathrm{m}$. (c) - (d) Flow velocity components along the transect at $x=-50 \mu \mathrm{m}$. The selected tracer particles are in the focal plane when $x=-20 \mu \mathrm{m}$, and using model streamlines in the $x z$-plane, we estimate that they are at $z=30 \mu \mathrm{m}$ when $x=-50 \mu \mathrm{m}$. Measurements (red dots) and leastsquares fit (blue lines) with the force magnitude as the only free parameter.

The point force model provides a description of the feeding flow of the individual on the coverslip [Fig. 2(a)], and it allows us to estimate the magnitude of the flow-generating force. We assume that the point force is positioned at the center of the tips of the frontal membranelles and directed parallel to the surface. We cannot directly observe the height of the frontal membranelles above the surface, and instead we use the profile view of the individual on a lump of material [Fig. 4(a),(b)]. To determine the magnitude of the flowgenerating force, $F$, we treat it as the only free parameter in a least-squares fit of the measured velocity components $v_{x}$ and $v_{y}$ along the transect with $x=-50 \mu \mathrm{m}$. With 
$h=30 \mu \mathrm{m}, z=30 \mu \mathrm{m}$, and $\mu=1.0 \times 10^{-3} \mathrm{Pas}$ [43], we find $F=260 \pm 4 \mathrm{pN}$. The standard deviation in $F$ is estimated using the standard deviation in the measured velocity components obtained directly from the observations [44]. We cannot assess the goodnessof-fit, since we do not have an independent estimate of the standard deviation in the measured velocity components, but both $v_{x}$ and $v_{y}$ appear to be in good agreement with the model [Fig. 4(c),(d)]. This suggests that the transect is sufficiently far from the organism for the far-field approximation of the point force model to be applicable.

\subsection{The flow along and through the membranelle band}

To observe the flow along and through the membranelle band, we use small tracer particles that are $2 \mu \mathrm{m}$ in diameter and can pass in between the membranelles (supplemental material, Video S6). The feeding flow approaches the anterior end of the membranelle band on its inner side. Some particles are transported along the membranelle band and end up in the mouth region, whereas others move some distance along the membranelle band and then through it and away from the organism (Fig. 5). In the feeding flow, food particles that are too large to pass in between neighboring membranelles will therefore be retained and up-concentrated in the mouth region. This picture is qualitatively similar to the description by Fenchel of the feeding flow in Euplotes moebiusi [3, 7]. 


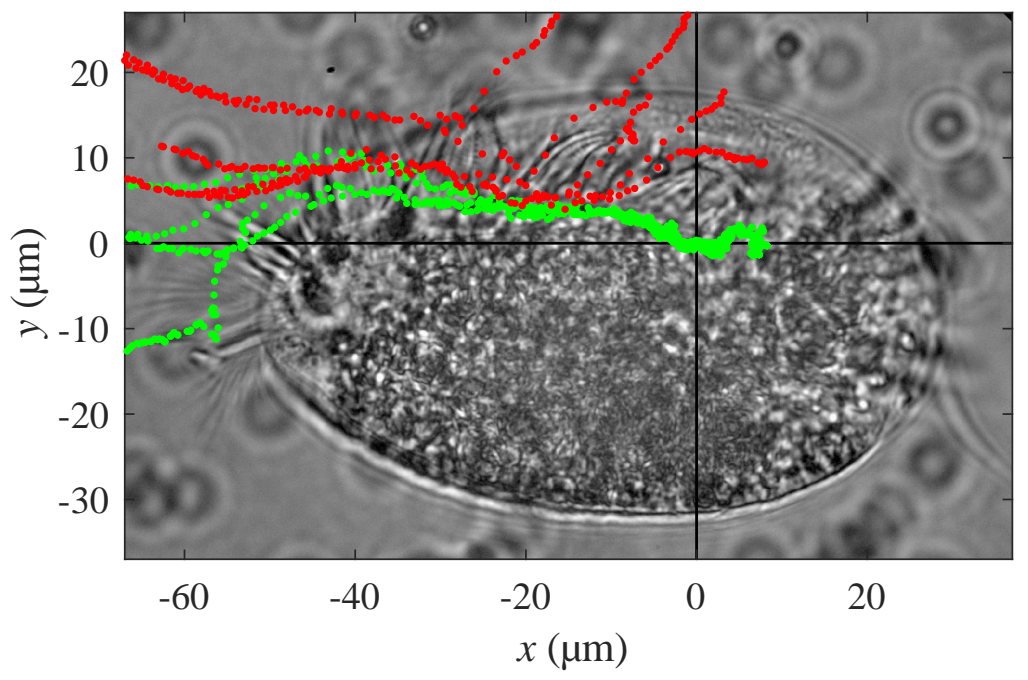

Figure 5: Visualization of the membranelle flow. Tracer particles that are transported along the inner side of the membranelle band to the mouth region (green) or outwards through the membranelle band (red). The particles are $2 \mu \mathrm{m}$ in diameter and shown with $2 \mathrm{~ms}$ time intervals. The particle tracks are shown relative to a coordinate system with the origin positioned in the mouth region and the $x$-axis oriented in the main flow direction along the membranelle band. 
(a)

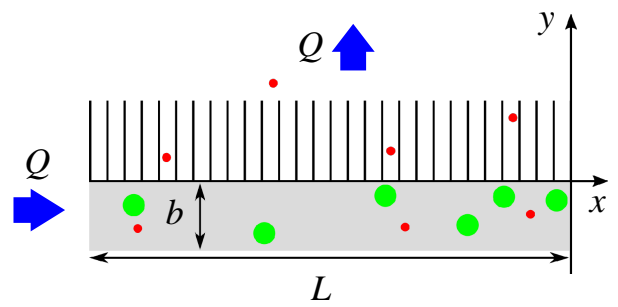

(b)

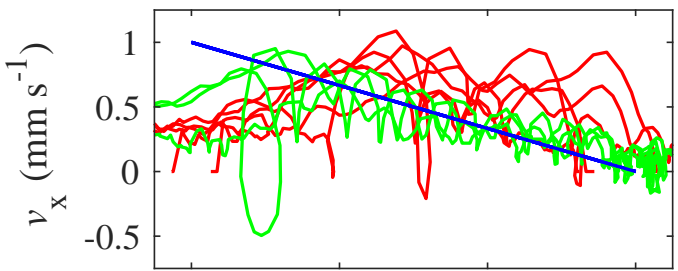

(c)

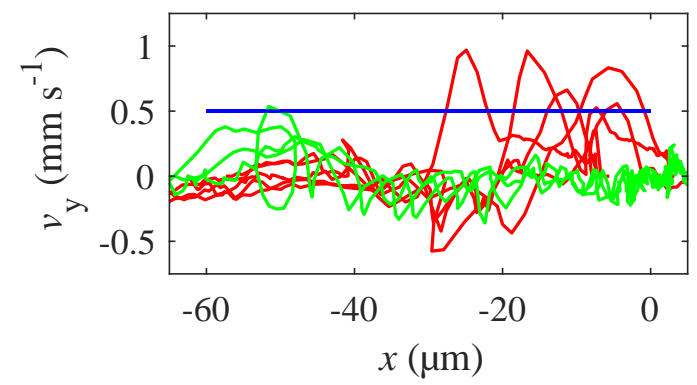

Figure 6: Velocity components in the membranelle flow. (a) Simple model of membranelle flow and particle retention. Particles with diameter smaller than the distance between neighboring membranelles can pass outwards between the membranelles, whereas large particles are retained and transported along the inner side of the membranelle band to the mouth region. (b) - (c) Velocity components in the flow based on particle tracks (green and red) and model results (blue) based on Eqs. (3) and (4). The tracer particles are all $2 \mu \mathrm{m}$ in diameter. Some of the particles pass through the membranelle band, whereas others are retained and transported to the mouth region. 
We can set up a simple model by disregarding the curvature of the membranelle band and assuming that the flow enters in the $x$-direction with flow rate $Q$ on the inner side of the membranelle band of length $L$ and goes through it in the $y$-direction [Fig. 6(a)]. The velocities of the particles that are transported along the membranelle band decrease as the mouth region is approached [Fig. 6(b)], and the particles that pass the membranelle band do so with velocities that are roughly the same irrespective of where the passage takes place [Fig. 6(c)]. We suggest the model flow:

$$
\begin{aligned}
& v_{x}=-\frac{Q x}{a b L}, \\
& v_{y}=\frac{Q}{a L},
\end{aligned}
$$

where $a$ and $b$ represent, respectively, the membranelle height and the width of the region with flow along the inner side of the membranelle band [Fig. 6(a)]. With the parameter values $Q=9 \times 10^{5} \mathrm{\mu m}^{3} \mathrm{~s}^{-1}, a=20 \mu \mathrm{m}, b=30 \mu \mathrm{m}$, and $L=92 \mu \mathrm{m}$, we obtain the estimate $v_{x}=1 \mathrm{~mm} \mathrm{~s}^{-1}$ when $x=-60 \mu \mathrm{m}$ in agreement with the measured velocities towards the mouth region (green) [Fig. 6(b)], and, as expected, our estimate of the average flow velocity through the membranelle band, $v_{y}=0.5 \mathrm{~mm} \mathrm{~s}^{-1}$, is lower than the peak velocities of the particles that pass the membranelle band (red) [Fig. 6(c)]. (See Sec. 3.5 for comparison of the peak velocities of the particles that pass the membranelle band and the metachronal wave velocity along the individual membranelles.)

\subsection{Metachronal motion and membranelle filtration}

The flow is driven by the metachronal motion of the membranelles, which we have explored by tracking the tips of the inner- and outermost cilia in a single individual (supplemental material, Video S7). We could track the motion of 16 membranelles in total. In seven membranelles we followed both the inner- and outermost cilia for 10 beat cycles, and in nine membranelles we could only observe the outermost ones (Fig. 7). In the power stroke that lasts approximately $1 / 3$ of the beat period $T=42 \pm 1 \mathrm{~ms}$, the cilia move quickly towards the mouth region, and in the return stroke they move slowly back. The initiation of the power stroke propagates along the membranelle band in the negative $x$-direction, and the phase of the beat motion is repeated after approximately seven membranelle gaps. The cilia in a membranelle do not move synchronously, and to determine their motion, we look at a single membranelle (Fig. 8). The initiation of the power stroke propagates outwards along the membranelle in the $y$-direction, and the innermost cilia finish the power stroke at the same time as the outermost ones start it. In summary, we see a metachronal wave that propagates along the membranelle band opposite to the power stroke (antiplectic) and outwards along the individual membranelle (dexioplectic) [19, 20]. 

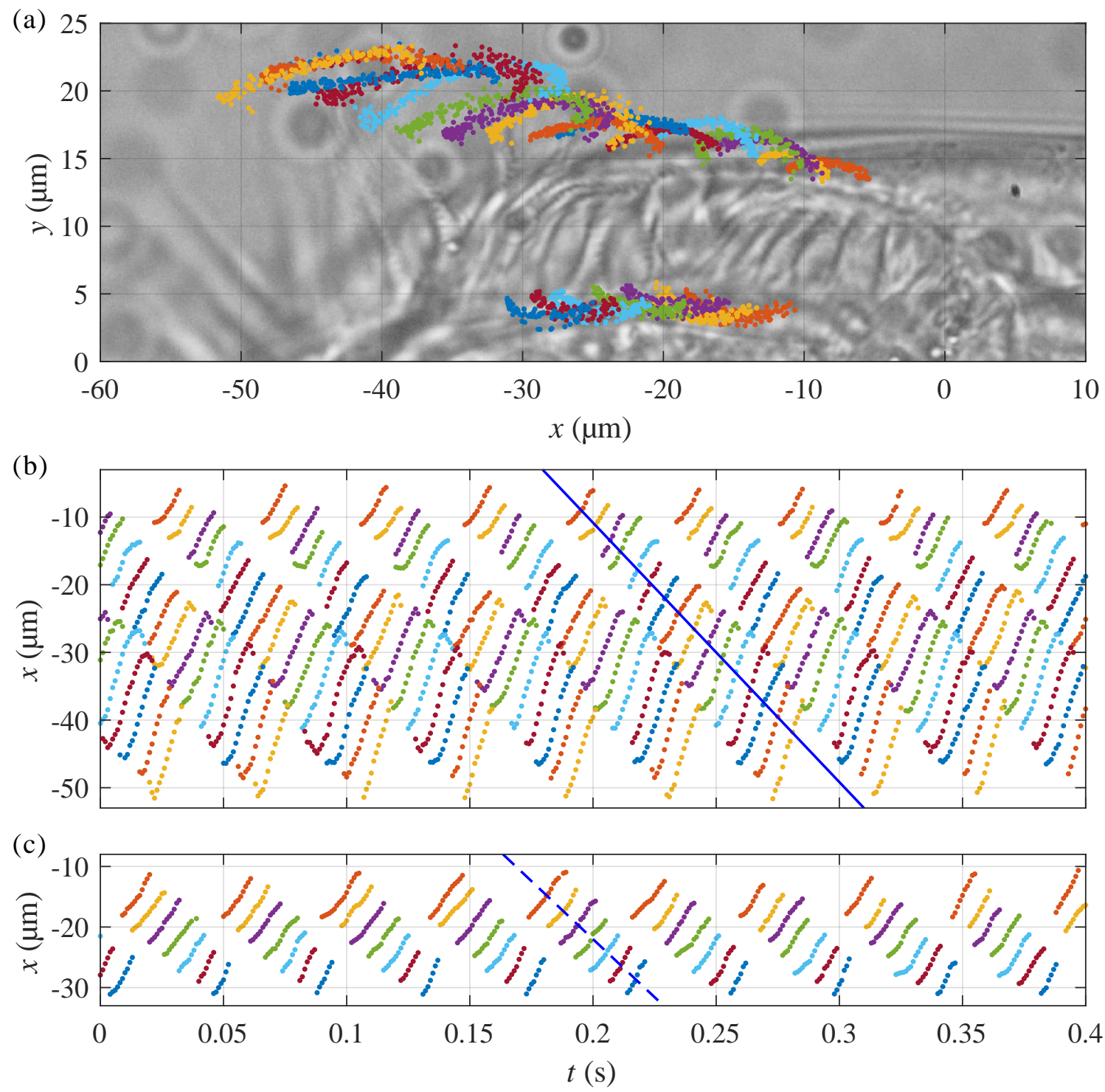

Figure 7: Metachronal motion in the membranelle band for ten beat cycles. (a) Membranelle tip positions superimposed on a still image from the video, and (b) the $x$ components of the outermost tip positions and (c) the innermost tip positions as functions of time. The membranelles are colored using a sequence of seven different colors, since the phase of the beat motion is repeated after approximately seven membranelle gaps. The inner membranelle positions correspond to the outer membranelle positions with identical color coding closest to the mouth region, and the data set has gaps since the cilia could only be identified during the power strokes. The metachronal wave velocity along the membranelle band and the phase difference between the inner- and outermost cilia of the individual membranelles are described by the two blue theory lines. (See Fig. 11 for details.) 

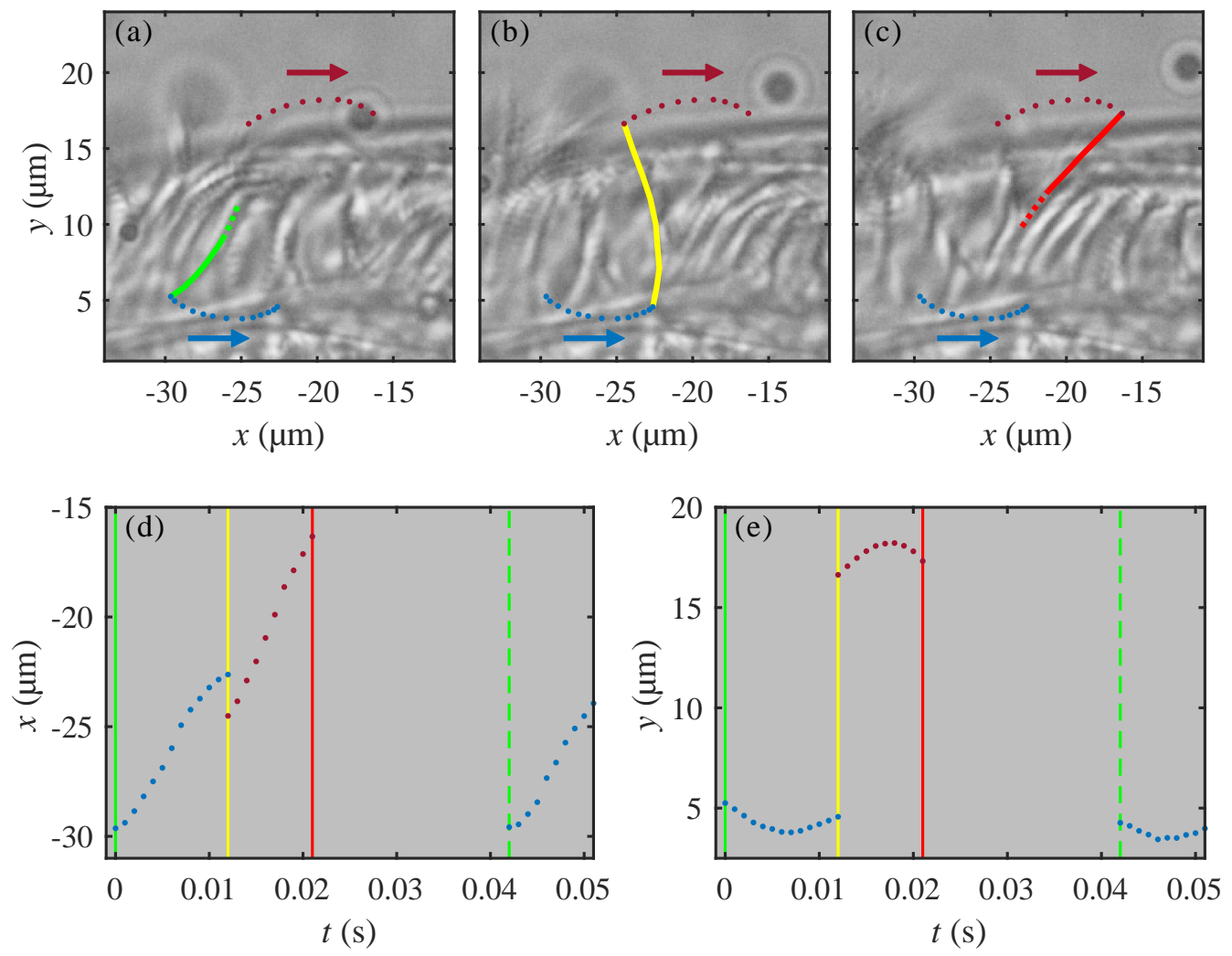

Figure 8: Phase difference across an individual membranelle. (a) - (c) Innermost (blue) and outermost (dark red) tip positions during the power stroke, and three snapshots of the tips when the innermost cilia start the power stroke (green), the innermost cilia finish and the outermost cilia start (yellow), and the outermost cilia finish (red). The arrows indicate the direction of motion in the power stroke. (d) - (e) The $x$ - and $y$-components of the innermost (blue) and the outermost (dark red) tip positions as functions of time. The snapshots in panels (a) - (c) correspond to the solid lines, and the beat period is indicated by the dashed lines in panels $(\mathrm{d})-(\mathrm{e})$. 
To understand how the beating membranelles generate water flow through the membranelle band while retaining large particles, we consider two neighboring membranelles and a small tracer particle for one beat cycle (Fig. 9). The leftmost of the two membranelles follows the rightmost with a time delay of approximately $1 / 7$ of the beat period as can be seen by comparing images with $6 \mathrm{~ms}$ time difference in the time series. In the first image, the rightmost of the two membranelles starts its power stroke, while the leftmost is still carrying out its return stroke. On the inner side of the band, a gap therefore opens between the two membranelles, and the tracer particle is drawn in between them. As the two membranelles finish their power strokes, they approach each other and push the tracer particle outwards and through the membranelle band. The two membranelles are close after completing their power strokes and they remain close in their return strokes.

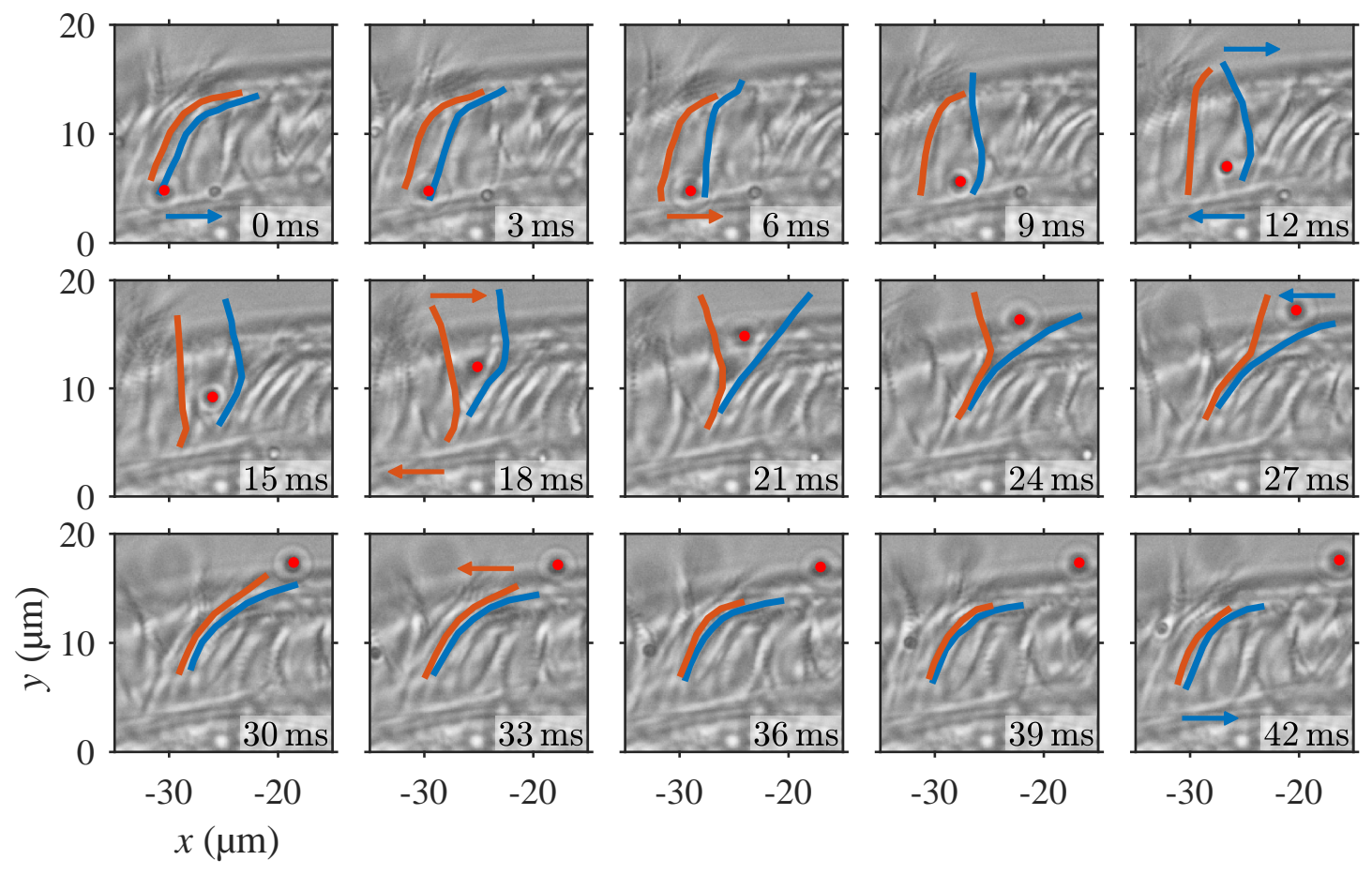

Figure 9: Time series of two neighboring membranelles through one beat cycle. A tracer particle is moved by the two membranelles outwards through the membranelle band during the beat cycle. The particle is $1 \mu \mathrm{m}$ in diameter and marked by a red dot, and the membranelles are highlighted in orange and blue. The arrows indicate the directions of motion of the inner- and outermost cilia, and they are shown in the frames in which the cilia start the power and the return stroke, respectively. The beat period is $T=42 \mathrm{~ms}$, and the time instant of each frame is shown in its lower right corner. 


\subsection{Model of membranelle filtration}

To model the metachronal motion of the membranelles, we assume that the cilia move periodically in the length direction of the membranelle band with fast power strokes and slow return strokes with constant speeds. For simplicity, we describe the cilium by a single variable, $q$, that represents the $x$-coordinate of the tip. Our model takes the form:

$$
q= \begin{cases}x-A+\frac{A}{\pi \alpha} \bmod (\varphi, 2 \pi) & \text { for } \quad 0 \leq \bmod (\varphi, 2 \pi)<2 \pi \alpha \\ x+A-\frac{A}{\pi(1-\alpha)}[\bmod (\varphi, 2 \pi)-2 \pi \alpha] & \text { for } \quad 2 \pi \alpha \leq \bmod (\varphi, 2 \pi)<2 \pi\end{cases}
$$

where $A$ is the amplitude and $\alpha$ the fractional duration of the power stroke. The phase, $\varphi$, depends as for a propagating line wave on time and space:

$$
\varphi=\omega t-k_{x} x-k_{y} y+\chi,
$$

where $x$ and $y$ are the coordinates of the base of the cilium, $\omega=2 \pi f$ the angular beat frequency, $k_{x}$ and $k_{y}$ the wave vector components of the metachronal wave, and $\chi$ the phase shift (Fig. 10). The tip of the cilium is at its leftmost position $q=x-A$ when $\varphi=0$, the power stroke brings it to the rightmost position $q=x+A$ when $\varphi=2 \pi \alpha$, and finally the return stroke brings it back to the leftmost position.

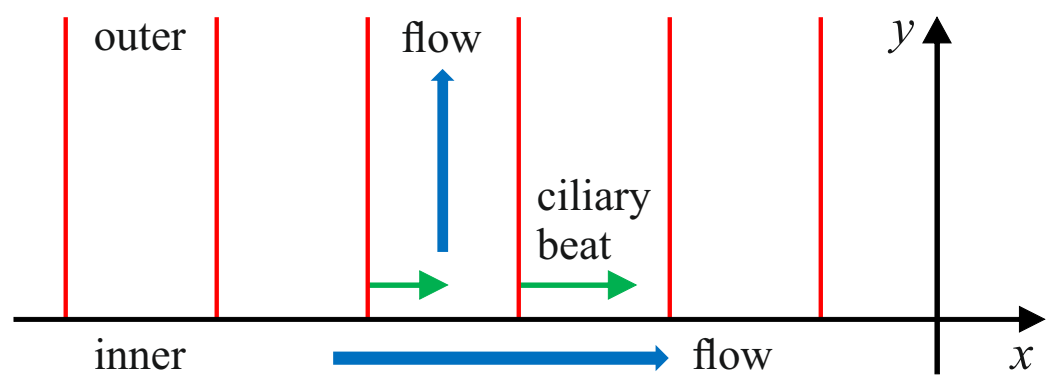

Figure 10: Geometry of membranelle band model. The cilia in the membranelles (red) are assumed to move periodically with the power stroke (green arrows) in the $x$-direction, and the water flow (blue arrows) goes along the membranelle band towards the mouth region on the inner side and outwards through the membranelle band in between the membranelles.

We complete the model by suggesting the wave vector components:

$$
\begin{aligned}
& k_{x}=-\frac{2 \pi}{N d}, \\
& k_{y}=\frac{2 \pi \alpha}{W},
\end{aligned}
$$


where $N$ is the number of membranelle gaps after which the phase is repeated along the band, $d$ the distance between the base of neighboring membranelles, and $W$ the width of the membranelles. The expressions build on our observations, and they lead to predictions about the membranelle filtration. From the constant phase relations:

$$
\begin{aligned}
& \omega \mathrm{d} t-k_{x} \mathrm{~d} x=0, \\
& \omega \mathrm{d} t-k_{y} \mathrm{~d} y=0,
\end{aligned}
$$

we obtain the propagation velocities of the metachronal wave along the membranelle band and along the individual membranelles:

$$
\begin{aligned}
\frac{\mathrm{d} x}{\mathrm{~d} t} & =\frac{\omega}{k_{x}}=-\frac{N d}{T}, \\
\frac{\mathrm{d} y}{\mathrm{~d} t} & =\frac{\omega}{k_{y}}=\frac{W}{\alpha T} .
\end{aligned}
$$

Due to the antiplectic nature of the metachronal wave $[19,20]$, there is a large gap between neighboring membranelles in the power stroke whereas neighboring membranelles are close in the return stroke (Fig. 9). To ensure that neighboring membranelles do not collide during the return strokes, we require that the cilia in the return strokes do not overtake the metachronal wave as it propagates along the membranelle band:

$$
v_{\mathrm{r}} \leq\left|\frac{\mathrm{d} x}{\mathrm{~d} t}\right|
$$

where $v_{\mathrm{r}}$ is the speed of the cilia during the return strokes:

$$
v_{\mathrm{r}}=\frac{2 A}{(1-\alpha) T} \text {. }
$$

The amplitude, $A$, must therefore be less than or equal to the maximum amplitude:

$$
A_{\max }=\frac{1}{2}(1-\alpha) N d \text {. }
$$

When two neighboring membranelles are both moving with either power or return strokes, the gap spacing between them is respectively:

$$
\begin{aligned}
& d_{\mathrm{p}}=\left(1-\beta+\frac{\beta}{\alpha}\right) d \\
& d_{\mathrm{r}}=(1-\beta) d
\end{aligned}
$$

where we have used the definition $\beta=A / A_{\max }$ and the expression for the speed of the cilia during the power strokes:

$$
v_{\mathrm{p}}=\frac{2 A}{\alpha T} .
$$



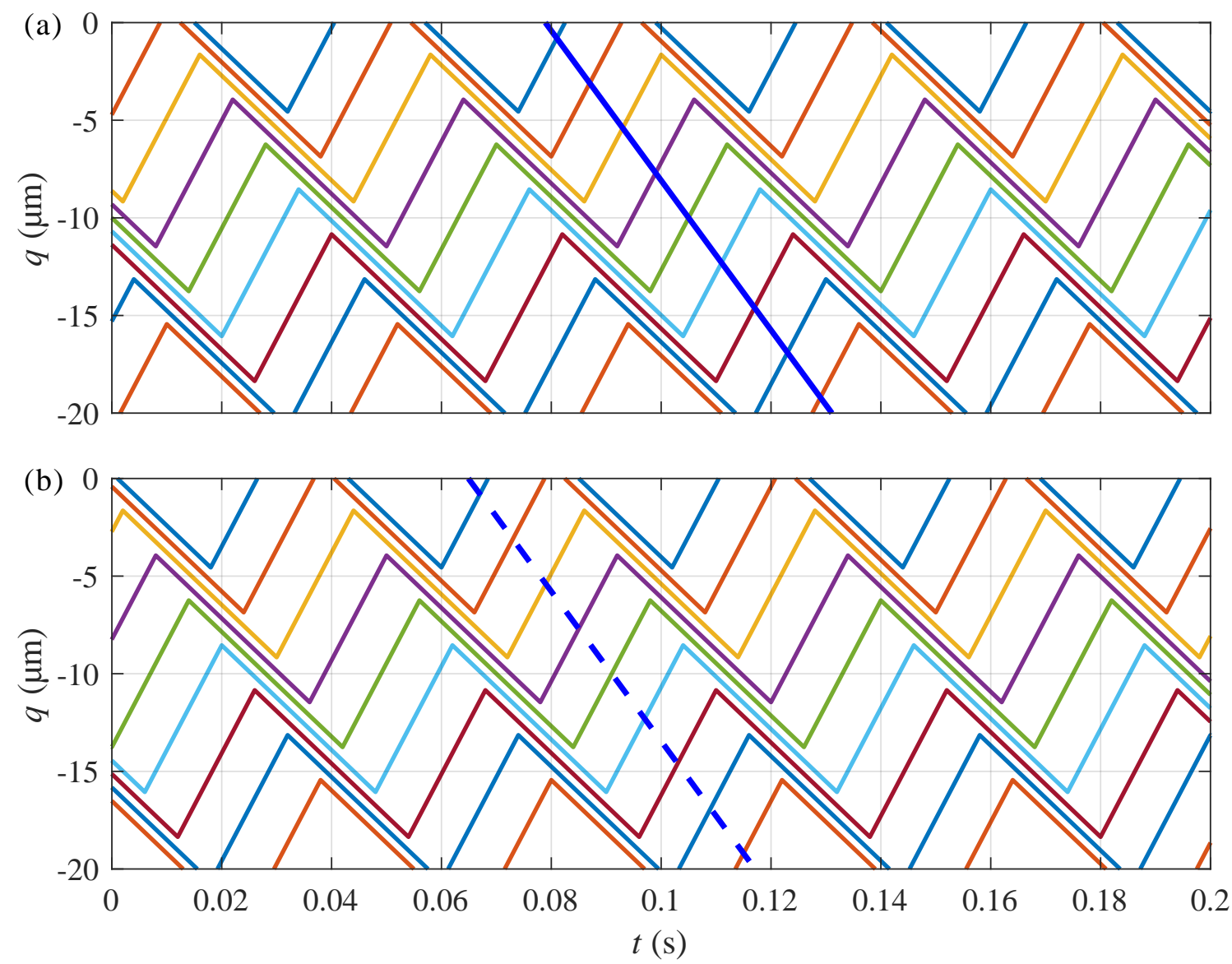

Figure 11: Model of the metachronal motion in the membranelle band. (a) The outermost and (b) innermost ciliary beat positions as functions of time with the parameter values $T=42 \mathrm{~ms}, \alpha=1 / 3, \beta=0.7, N=7, d=2.3 \mu \mathrm{m}$, and $W=12 \mu \mathrm{m}$. The blue lines are based on Eq. (11) and the observed phase difference between the inner- and outermost cilia of the individual membranelles. The slope of the blue lines, $\mathrm{d} x / \mathrm{d} t=-0.4 \mathrm{~mm} \mathrm{~s}^{-1}$, models the metachronal wave velocity along the membranelle band. See Fig. 7 for comparison of the theoretical lines and the observed membranelle motion.

To explore the model predictions, we plot the outermost and innermost ciliary beat positions as functions of time (Fig. 11). The phase shift is chosen so that the membranelle (green) centered at $q=-10 \mu \mathrm{m}$ starts the power stroke on the inner side when $t=0$. The power stroke of the membranelle finishes on the inner side and starts on the outer side when $t=\alpha T=14 \mathrm{~ms}$, and the metachronal wave propagates in agreement with our observations (Fig. 7). Furthermore, the gap between neighboring membranelles opens from the inner side of the band and closes subsequently in qualitatively the same manner 
in experiment and model (Fig. 12). To model the clearance rate, we consider the volume, $V$, between neighboring membranelles when the innermost cilia of the two membranelles first come close in the return stroke as in the panels with $t=20 \mathrm{~ms}$. The volume becomes:

$$
V=a W d\left[1-\beta+\frac{\beta}{\alpha}\left(1-\frac{1}{2 \alpha N}\right)\right],
$$

where $a$ is the membranelle height. If we assume that the clearance rate per membranelle gap is $V / T$, we find the clearance rate through the membranelle band:

$$
Q=\frac{L V}{d T}=\frac{L a W}{T}\left[1-\beta+\frac{\beta}{\alpha}\left(1-\frac{1}{2 \alpha N}\right)\right]
$$

since $L / d$ is the total number of gaps in the membranelle band of length $L$. With the parameter values $T=42 \mathrm{~ms}, \alpha=1 / 3, \beta=0.7, N=7, W=12 \mu \mathrm{m}, a=20 \mu \mathrm{m}$, and $L=92 \mu \mathrm{m}$, we find the estimate $Q=1.0 \times 10^{6} \mathrm{\mu m}^{3} \mathrm{~s}^{-1}$ and the metachronal wave velocity along the individual membranelles $\mathrm{d} y / \mathrm{d} t=0.9 \mathrm{~mm} \mathrm{~s}^{-1}$ in agreement with the clearance rate of the feeding flow, $Q=(9 \pm 2) \times 10^{5} \mathrm{\mu m}^{3} \mathrm{~s}^{-1}$, and the observed peak velocities of the particles that pass the membranelle band [Fig. 6(c)]. Finally, we estimate the gap spacing in the power stroke $d_{\mathrm{p}}=5.5 \mu \mathrm{m}$ and the return stroke $d_{\mathrm{r}}=0.7 \mu \mathrm{m}$, where we have used Eqs. (16) and (17) and the membranelle spacing $d=2.3 \mu \mathrm{m}$.

\section{Discussion}

We found that the feeding flow of E. vannus is predominantly parallel to the surface in contrast to the perpendicular feeding flow of Vorticella sp. and other ciliates that attach with a long stalk $[3,6,7,39]$. The observed flow velocities $50 \mu \mathrm{m}$ upstream of the ciliate appear to be in good agreement with the point force model, and our force estimate $F=260 \pm 4 \mathrm{pN}$ based on experiment and model is consistent with the estimated range from $50 \mathrm{pN}$ to $500 \mathrm{pN}$ for the flow-generating force in the similarly sized Vorticella convallaria [39]. The model suggests that the reduction of the feeding flow due to the proximity of the surface is twice as large when the flow is perpendicular to the surface compared with the parallel case, and that this allows suspension feeders with parallel feeding flow to be positioned comparatively close to the surface [3, 40]. The membranelle band on the ventral side of the cell is close above the surface, and it seems plausible that this facilitates feeding on food particles that are directly on the surface and that the surface helps in directing the feeding flow towards the membranelle band.

Our high-speed video observations show that the power strokes are directed parallel to the membranelle band towards the mouth region, and that the metachronal wave propagates forwards from the mouth region along the membranelle band and outwards along the individual membranelles as described schematically by Fenchel [3, Fig. 13]. The antiplectic motion results in large gaps between neighboring membranelles in the power strokes $[19$, 


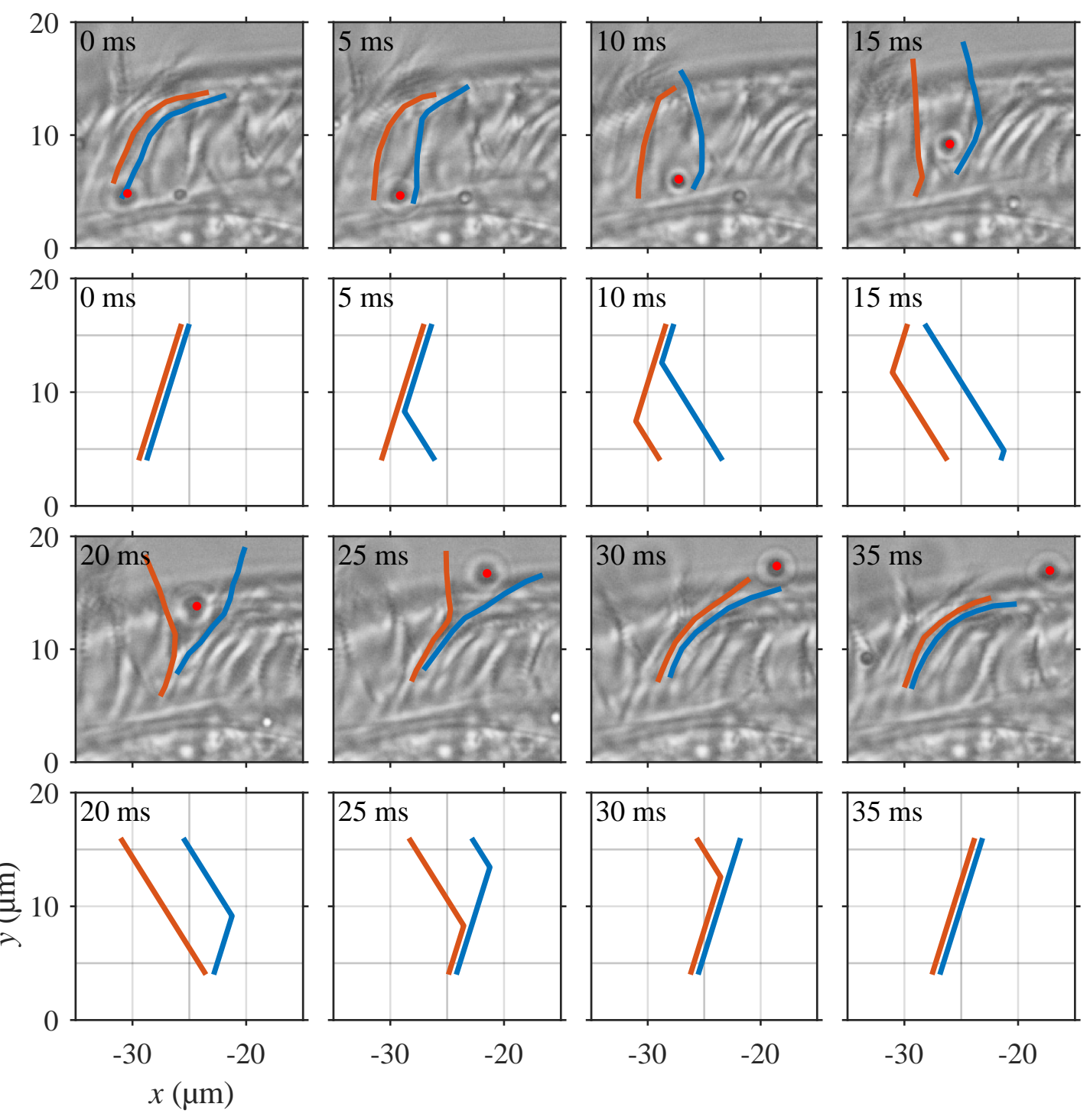

Figure 12: Time series of two neighboring membranelles and a tracer particle through one beat cycle in the experiment (gray images) and the model with the parameter values $T=42 \mathrm{~ms}, \alpha=1 / 3, \beta=0.7, N=7, d=2.3 \mu \mathrm{m}$, and $W=12 \mu \mathrm{m}$. The particle is $1 \mu \mathrm{m}$ in diameter and marked by a red dot, and the membranelles are highlighted in orange and blue. The phase shift is chosen so that the rightmost membranelle (blue) starts the power stroke on the inner side when $t=0$.

20], and it leads to efficient generation of flow towards the mouth region in analogy with the result found in arrays of artificial cilia [45]. Furthermore, the flow through the mem- 
branelle band is outwards in the direction of the metachronal wave along the individual membranelles (Fig. 12). The time series of the tracer particle and the two neighboring membranelles suggests that neighboring membranelles function as a sluice in which a volume of water is drawn in on the inner side of the band and subsequently pushed out on the outer side. The power stroke of the outermost cilia starts when the power stroke of the innermost cilia finishes, and this ensures the coordinated opening and closing of the gap between neighboring membranelles and enables the sluice function.

To sustain a population in the food sparse marine environment, suspension feeders need to clear a volume of water equivalent to about one million times their cell volume per day [2]. Consistent with this general observation, we estimated the cell-volume specific clearance rate $(1.7 \pm 0.3) \times 10^{6} \mathrm{~d}^{-1}$ directly from the feeding flow, and this was supported by our estimates based on the particle tracks through the membranelle band and our model of the membranelle filtration. Our direct flow observations using single individuals of E. vannus are in agreement with the cell-volume specific clearance rate found in grazing experiments averaged across many individuals [3, Fig. 28]. Furthermore, the soft lower cutoff in the prey size spectra of upstream collectors suggests that the effective gap spacing varies between $d$ at the cell surface and $d_{\mathrm{p}}$ at the tips of the cilia, and our observed values of $d=2.3 \mu \mathrm{m}$ and $d_{\mathrm{p}}=5.5 \mu \mathrm{m}$ are in agreement with the prey size spectrum for the largest size class of E. vannus reported by Fenchel [3, Fig. 26].

Clearance rate and membranelle gap depend on both geometry and kinematics, and we find the rough approximations $Q \approx L a W /(\alpha T)$ and $d_{\mathrm{p}} \approx d / \alpha$ if the amplitude is close to its maximum in Eqs. (16) and (20). The approximations suggest that $Q$ and $d_{\mathrm{p}}$ are inversely proportional to the fractional duration of the power stroke, $\alpha$, and that decreasing $\alpha$ will increase the clearance rate at the cost of a more leaky filter. For a given size distribution of potential prey, this trade-off between clearance rate and membranelle gap suggests that there must be an optimal $\alpha$ for which the prey mass encounter rate is the highest. To quantify the trade-off, we estimate the encounter rate:

$$
E=Q\left(\int_{d}^{d_{\mathrm{p}}} \frac{s-d}{d_{\mathrm{p}}-d} C(s) \mathrm{d} s+\int_{d_{\mathrm{p}}}^{l} C(s) \mathrm{d} s\right),
$$

where $C$ is the size-specific mass concentration of food particles and $s$ the food particle diameter. The first term models the soft lower cut-off in the prey size spectrum by a linearly increasing retention efficiency, and the second term assumes $100 \%$ retention of food particles between $d_{\mathrm{p}}$ and the upper cut-off, $l$, which is determined by the size of the mouth region [3]. Logarithmic size classes in the marine environment contain roughly the same biomass [46], and we therefore use the size-specific mass concentration:

$$
C(s)=\frac{C_{0} / \ln 10}{s},
$$

where $C_{0}$ is the mass concentration within each decade in food particle diameter. With 
these assumptions, our estimate of the encounter rate becomes:

$$
E=\frac{Q C_{0}}{\ln 10}\left(1-\frac{d}{d_{\mathrm{p}}-d} \ln \frac{d_{\mathrm{p}}}{d}+\ln \frac{l}{d_{\mathrm{p}}}\right),
$$

where $Q$ and $d_{\mathrm{p}}$ are given by Eqs. (16) and (20). As a simple parameter exploration, we find the maximum encounter rate at $\alpha=0.4$ when $l=8 \mu \mathrm{m}$ and $\alpha=0.3$ when $l=10 \mu \mathrm{m}$, where we have used $\beta=0.7, N=7$, and $d=2.3 \mu \mathrm{m}$. This result is consistent with our observation $\alpha=1 / 3$ and the prey size spectrum for E. vannus with $l=8-10 \mu \mathrm{m}[3]$. The prey size spectra in ciliates and other filter feeders are narrow compared to other quantitatively important grazers on $2-30$ micron sized phytoplankton and flagellates, such as dinoflagellates and copepods that perceive and capture rather than filter out individual prey [47-50]. In such suspension feeding modes there is no tradeoff between clearance rate and retention efficiency, and the lower prey size threshold is governed by sensing capability. Despite the narrow prey size spectrum, ciliates are able to compete due to their high growth rate [51], allowing them to respond to ephemeral patches of food.

\section{Acknowledgments}

We are grateful to Rocío Torres for help in maintaining the cell culture, Erik Hansen for his careful work on design and construction of equipment for the experiments, Per Juel Hansen for discussions of ciliate characteristics, and Massimiliano Rossi and Uri Shavit for advice on particle tracking and data analysis. This work was supported by The Independent Research Fund Denmark (grant no. 7014-00033B), the Centre for Ocean Life, a VKR Centre of Excellence supported by the Villum Foundation, and the Carlsberg Foundation (grant no. CF17-0495).

\section{References}

1. Jørgensen, C. B. (1983). "Fluid mechanical aspects of suspension feeding". Mar. Ecol. Prog. Ser. 11, 89-103. DOI: 10.3354/meps011089.

2. Kiørboe, T. (2011). "How zooplankton feed: mechanisms, traits and trade-offs". Biol. Rev. 86, 311-339. DOI: 10.1111/j.1469-185X.2010.00148.x.

3. Fenchel, T. (1986). "Protozoan Filter Feeding". Prog. Protistol. 1, 65-113.

4. Kiørboe, T. (2016). "Fluid dynamic constraints on resource acquisition in small pelagic organisms". Eur. Phys. J. Special Topics 225, 669-683. DOI: 10.1140/epjst/ e2015-50261-1.

5. Jabbarzadeh, M. and Fu, H. C. (2018). "Viscous constraints on microorganism approach and interaction". J. Fluid Mech. 851, 715-738. DOI: 10.1017/jfm.2018.509. 
6. Sleigh, M. A. and Barlow, D. (1976). "Collection of Food by Vorticella". Trans. Am. Microsc. Soc. 95, 482-486. DOI: 10.2307/3225140.

7. Fenchel, T. (1980). "Suspension feeding in ciliated protozoa - Structure and function of feeding organelles". Arch. Protistenkunde 123, 239-260. DOI: 10 . 1016/S00039365 (80) 80009-1.

8. Magar, V., Goto, T., and Pedley, T. J. (2003). "Nutrient uptake by a self-propelled steady squirmer". Q. J. Mech. Appl. Math. 56, 65-91. DOI: 10.1093/qjmam/56.1.65.

9. Guasto, J. S., Rusconi, R., and Stocker, R. (2012). "Fluid Mechanics of Planktonic Microorganisms". Annu. Rev. Fluid Mech. 44, 373-400. DOI: $10.1146 /$ annurevfluid-120710-101156.

10. Ishikawa, T., Kajiki, S., Imai, Y., and Omori, T. (2016). "Nutrient uptake in a suspension of squirmers". J. Fluid Mech. 789, 481-499. DOI: 10.1017/jfm.2015.741.

11. Lauga, E. (2020). The fluid dynamics of cell motility. Cambridge University Press. DOI: $10.1017 / 9781316796047$.

12. Lighthill, M. J. (1952). "On the squirming motion of nearly spherical deformable bodies through liquids at very small Reynolds numbers". Communications on Pure and Applied Mathematics 5, 109-118. DOI: 10.1002/cpa.3160050201.

13. Blake, J. R. (1971). "A spherical envelope approach to ciliary propulsion". J. Fluid Mech. 46, 199-208. DOI: 10.1017/S002211207100048X.

14. Blake, J. R. and Sleigh, M. A. (1974). "Mechanics of Ciliary Locomotion". Biol. Rev. 49, 85-125. DOI: $10.1111 / \mathrm{j} .1469-185 \mathrm{X} .1974$. tb01299.x.

15. Eloy, C. and Lauga, E. (2012). "Kinematics of the Most Efficient Cilium". Phys. Rev. Lett. 109, 038101. DOI: 10.1103/PhysRevLett.109.038101.

16. Ito, H., Omori, T., and Ishikawa, T. (2019). "Swimming mediated by ciliary beating: comparison with a squirmer model". J. Fluid Mech. 874, 774-796. DOI: 10.1017/ jfm. 2019.490.

17. Gray, J. (1930). "The mechanism of ciliary movement - VI Photographic and stroboscopic analysis of ciliary movement". Proc. Roy. Soc. B 107, 313-332. DOI: 10 . 1098/rspb. 1930.0075.

18. Sleigh, M. A. (1960). "The form of beat in cilia of Stentor and Opalina". J. Exp. Biol. 37, 1-10. DOI: 10.1242/jeb.37.1.1.

19. Knight-Jones, E. W. (1954). "Relations between Metachronism and the Direction of Ciliary Beat in Metazoa". Q. J. Microsc. Sci. 95, 503-521.

20. Machemer, H. (1974). "Ciliary activity and metachronism in Protozoa". Cilia and flagella. Ed. by M. A. Sleigh. Academic Press, London, New York.

21. Horridge, G. A. and Tamm, S. L. (1969). "Critical Point Drying for Scanning Electron Microscopic Study of Ciliary Motion". Science 163, 817-818. DOI: 10.1126/science. 163.3869.817.

22. Tamm, S. L. (1972). "Ciliary motion in Paramecium: A scanning electron microscope study". J. Cell Biol. 55, 250-255. DOI: 10.1083/jcb.55.1.250. 
23. Yih, W., Kim, H. S., Jeong, H. J., Myung, G., and Kim, Y. G. (2004). "Ingestion of cryptophyte cells by the marine photosynthetic ciliate Mesodinium rubrum". Aquat. Microb. Ecol. 36, 165-170. DOI: 10.3354/ame036165.

24. Esteban, G. F., Fenchel, T., and Finlay, B. J. (2010). "Mixotrophy in Ciliates". Protist 161, 621-641. DOI: $10.1016 / \mathrm{j}$.protis.2010.08.002.

25. Jiang, H. and Johnson, M. D. (2017). "Jumping and overcoming diffusion limitation of nutrient uptake in the photosynthetic ciliate Mesodinium rubrum". Limnol. Oceanogr. 62, 421-436. DOI: 10.1002/lno.10432.

26. Fenchel, T. (1980). "Relation between particle-size selection and clearance in suspensionfeeding ciliates". Limnol. Oceanogr. 25, 733-738. DOI: 10.4319/1o.1980 .25.4.0733.

27. Fenchel, T. (1980). "Suspension feeding in ciliated protozoa - functional-response and particle-size selection". Microb. Ecol. 6, 1-11. DOI: 10.1007/BF02020370.

28. Fenchel, T. (1980). "Suspension feeding in ciliated protozoa - feeding rate and their ecological significance". Microb. Ecol. 6, 13-25. DOI: 10.1007/BF02020371.

29. Strathmann, R. R., Jahn, T. L., and Fonseca, J. R. C. (1972). "Suspension feeding by marine invertebrate larvae: Clearance of particles by ciliated bands of a rotifer, pluteus, and trochophore". Biol. Bull. 142, 505-519. DOI: 10.2307/1540326.

30. Riisgård, H. U. and Larsen, P. S. (2010). "Particle capture mechanisms in suspensionfeeding invertebrates". Mar. Ecol. Prog. Ser. 418, 255-293. DOI: 10.3354/meps08755.

31. Müller, O. F. (1783). "Om Infusionsdyrenes Forplantningsmaader". Nye Samling af det Kongelige Danske Videnskabernes Selskabs Skrifter, 240-276.

32. Lynn, D. H. (2008). The ciliated protozoa: Characterization, classification, and guide to the literature. 3rd Edition, 1-605. DOI: 10.1007/978-1-4020-8239-9.

33. Tang, D., Wang, X., Dong, J., Li, Y., Gao, F., Xie, H., and Zhao, C. (2020). "MorpholinoMediated Knockdown of Ciliary Genes in Euplotes vannus, a Novel Marine Ciliated Model Organism". Front. Microbiol. 11, 2546. DOI: 10.3389/fmicb. 2020.549781.

34. Erra, F., Iervasi, A., Ricci, N., and Banchetti, R. (2001). "Movement of the cirri during the creeping of Euplotes crassus (Ciliata, Hypotrichida)". Can. J. Zool. 79, 1353-1362. DOI: 10.1139/z01-030.

35. Fenchel, T. (2004). "Orientation in two dimensions: chemosensory motile behaviour of Euplotes vannus". European Journal of Protistology 40, 49-55. DOI: 10.1016/j . ejop.2003.09.001.

36. Blake, J. R. (1971). "A note on the image system for a stokeslet in a no-slip boundary". Math. Proc. Cambridge Philos. Soc. 70, 303-310. DOI: 10.1017/S0305004100049902.

37. Blake, J. R. and Chwang, A. T. (1974). "Fundamental singularities of viscous flow". J. Eng. Math. 8, 23-29. DOI: 10.1007/BF02353701.

38. Pepper, R. E., Roper, M., Ryu, S., Matsudaira, P., and Stone, H. A. (2010). "Nearby boundaries create eddies near microscopic filter feeders". J. R. Soc. Interface 7, 851862. DOI: $10.1098 /$ rsif.2009.0419. 
39. Pepper, R. E., Roper, M., Rye, S., Matsumoto, N., Nagai, M., and Stone, H. A. (2013). "A New Angle on Microscopic Suspension Feeders near Boundaries". Biophys. J. 105, 1796-1804. DOI: 10.1016/j.bpj.2013.08.029.

40. Rode, M., Meucci, G., Seegert, K., Kiørboe, T., and Andersen, A. (2020). "Effects of surface proximity and force orientation on the feeding flows of microorganisms on solid surfaces". Phys. Rev. Fluids 5, 123104. DOI: 10.1103/PhysRevFluids.5.123104.

41. Lanczos, C. (1956). Applied Analysis. Prentice-Hall, Englewood Cliffs, New Jersey, USA, 321-324.

42. Anderssen, R. S. and Hoog, F. R. de (1984). "Finite difference methods for the numerical differentiation of non-exact data". Computing 33, 259-267. DOI: 10.1007 / BF02242272.

43. Kaye, G. W. C. and Laby, T. H. (1995). Tables of Physical and Chemical Constants. 16th Edition. Longman Group Limited.

44. Press, W. H., Teukolsky, S. A., Vetterling, W. T., and Flannery, B. P. (2007). Numerical Recipes. 3rd Edition. Cambridge University Press.

45. Milana, E., Zhang, R., Vetrano, M. R., Peerlinck, S., De Volder, M., Onck, P. R., Reynaerts, D., and Gorissen, B. (2020). "Metachronal patterns in artificial cilia for low Reynolds number fluid propulsion". Sci. Adv. 6, eabd2508. DOI: 10.1126/sciadv . abd2508.

46. Sheldon, R. W., Prakash, A., and Sutcliffe, W. H. (1972). "The size distribution of particles in the ocean". Limnol. Oceanogr. 17, 327-340. DOI: 10.4319/1o.1972.17. 3.0327.

47. Hansen, B., Bjørnsen, P. K., and Hansen, P. J. (1994). "The size ratio between planktonic predators and their prey". Limnol. Oceanogr. 39, 395-403. DOI: 10.4319/1o. 1994.39 .2 .0395$.

48. Hansen, P. J. and Calado, A. J. (1999). "Phagotrophic Mechanisms and Prey Selection in Free-living Dinoflagellates". J. Eukaryot. Microbiol. 46, 382-389. DOI: 10.1111/ j.1550-7408.1999.tb04617.x.

49. Naustvoll, L.-J. (2000). "Prey size spectra and food preferences in thecate heterotrophic dinoflagellates". Phycologia 39, 187-198. DOI: 10.2216/i0031-8884-39-3-187.1.

50. Ryderheim, F., Hansen, P. J., and Kiørboe, T. (2021). "Size as a defense in marine colony-forming phytoplankton". In review.

51. Hansen, P. J., Bjørnsen, P. K., and Hansen, B. W. (1997). "Zooplankton grazing and growth: Scaling within the 2-2,000- $\mu \mathrm{m}$ body size range". Limnol. Oceanogr. 42, 687-704. DOI: 10.4319/10.1997.42.4.0687. 